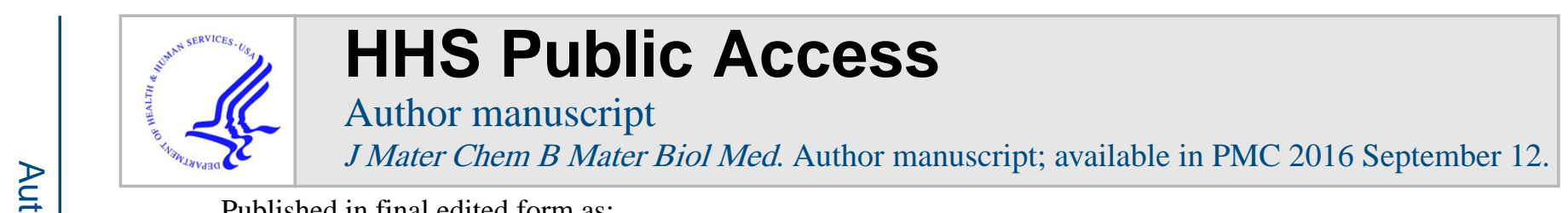

Published in final edited form as:

J Mater Chem B Mater Biol Med. 2016 ; 4: 1586-1599. doi:10.1039/C5TB01686J.

\title{
Tailoring biomaterial surface properties to modulate host- implant interactions: implication in cardiovascular and bone therapy
}

\author{
Settimio Pacellia ${ }^{\text {, Vijayan Manoharan }}{ }^{a}$, Anna Desalvo ${ }^{b}$, Nikita Lomis ${ }^{c}$, Kartikeya Singh \\ Jodha $^{a}$, Satya Prakash ${ }^{c}$, and Arghya Paula \\ aBiolntel Research Laboratory, Department of Chemical and Petroleum Engineering, \\ Bioengineering Graduate Program, School of Engineering, University of Kansas, Lawrence, KS, \\ USA. \\ bUniversity of Southampton, School of Medicine, University Road, Southampton SO17 1BJ, \\ United Kingdom. \\ 'Biomedical Technology and Cell Therapy Research Laboratory, Department of Biomedical \\ Engineering, Faculty of Medicine, Duff Medical Building, 3775 University Street, McGill University, \\ QC, Canada H3A 2B4.
}

\begin{abstract}
Host body response to a foreign medical device plays a critical role in defining its fate post implantation. It is thus important to control host-material interactions by designing innovative implant surfaces. In the recent years, biochemical and topographical features have been explored as main target to produce this new type of bioinert or bioresponsive implants. The review discusses specific biofunctional materials and strategies to achieve a precise control over implant surface properties and presents possible solutions to develop next generation of implants, particularly in the fields of bone and cardiovascular therapy.
\end{abstract}

\section{Introduction}

In recent years, biomaterial-based medical implants have gained much acceptance across the medical community because of their ability to modulate local inflammatory responses, replace or restore the integrity of damaged tissues that are no longer functional and attenuate adverse tissue reactions ${ }^{1}$. However, once they are implanted in the body a layer of plasma proteins such as fibrinogen, albumin and fibronectin can coat their surfaces that leads to adverse host responses such as coagulation, complement activation as well as the recruitment of innate immune cells. Acute inflammation is then generally followed by chronic immune responses ${ }^{2}$ that subsequently progress into a foreign body reaction. In this last stage macrophages can undergo fusion to form foreign body giant cells $\mathrm{s}^{3,4}$ and be responsible for the fibrosis encapsulation of the medical device. In most of the cases, this last step impose a major impediment for successful in vivo performance of the implant ${ }^{5}$. For

Correspondence to: Satya Prakash; Arghya Paul. 
example, in the case of cardiac pacemakers, formation of a dense capsule can attenuate the propagation of the electrical signal while in intravascular stents, fibrosis can cause a renarrowing of the stented area ${ }^{6}$.

Hence, it is imperative that we develop strategies to tailor the material surface properties before implanting them so as induce favourable host-material interactions. For instance, to design vascular grafts and heart valves we opt for biomaterials that can efficiently resist protein adhesions and eliminate the chance of thrombosis and immunogenic responses ${ }^{7}$. However, this paradigm is not applicable to all applications as immune response and the consequent remodelling can sometimes be important in defining the success of certain implants and for its integration with the host tissue ${ }^{8}$. This concept can be applied for example to bone grafts, in which the process of healing is regulated by close interactions among cells of the immune system, osteoclasts and osteoblasts ${ }^{9}$. Recently, macrophages have been considered as target to regulate bone morphogenesis due to their ability to polarize into pro-inflammatory and anti-inflammatory phenotypes and affect different stages of bone healing ${ }^{8}$. With more such evidences, biomaterials-based research is now focused on exploring immune modulation mechanisms to invent osteoinductive materials.

Furthermore, a precise understanding of the host response to changes in surface properties of biomedical implant is essential for fabricating a successful device for cardiac and bone applications ${ }^{10}$. In fact, surface chemistry and topography represent some of the important factors that can be effectively manipulated to control immunological responses such as cytokines expressions, monocyte differentiation, macrophage and dendritic cell activation and protein adsorption ${ }^{11,12}$. Chemical and topographical characteristics can be varied using several strategies to generate specific pattern or coatings on the biomaterial surface. Such coatings can also contain drugs or specific immunomodulatory proteins capable of exerting active control over the behaviour of local immune cells ${ }^{13}, 14$.

Our objective in this review is to delineate currently available techniques and strategies for controlling the surface properties of biomedical implants. Specifically, we will discuss the principles behind the preparation of both inert and immunomodulatory surfaces and the criteria governing their design. Further attention will be shed on how these strategies can be harnessed for fabricating new biocompatible medical implants for cardiac and bone applications. In addition, we will highlight the persisting impediments with these technologies and potential solutions for their successful applications in the field of cardiovascular and bone diseases.

\section{Bioinert surfaces: general considerations}

Interactions between host proteins and implant surfaces are linked with various important biological reactions and cascading effects of host immune system. Non-specific binding of unwanted proteins on the implant surface, also known as biofouling, can be one such type interaction that leads to graft rejection by host system. This early stage can lead to a foreign body reactions causing a possible implant failure. This process can be avoided by designing bioinert or biomimetic surfaces that can prevent protein adsorption and the accompanying immune responses. A possible strategy to achieve this goal is to modify the surface 
properties of implantable devices using biocompatible polymer coatings capable of limiting protein attachments ${ }^{15}$. These polymer layers should be mechanically and chemically robust to sustain surface deposition on the implant, withstand sterilization and implantation procedures and most importantly retain their stability in vivo. Such a polymer coating can help achieve better control over several critical parameters such as the surface free energy, chemical composition, wettability and steric repulsion.

Each of these key factors can be tweaked to control the protein adsorption by synthesizing polymers with suitable chemical, physical and interfacial free energy properties. Interfacial free energy provides a measure of the driving force for the adsorption of proteins and cells on to a solid surface influencing the host response to a biomaterial ${ }^{16}$. Thickness of the coating along with the temperature, pressure and friction of the surrounding biological fluids are some of the key factors that determine the free energy at the interface. Polymeric coatings with low interfacial energies to water and blood represents the best choice in order to reduce protein adsorption on implants. In addition, the chemical composition of the polymer used along with its wettability also play a significant role in determining the degree of protein entrapment ${ }^{17}$.

Generally, hydrophobic coatings have higher affinity for proteins with respect to hydrophilic ones as the adsorption generally occur through hydrophobic interactions ${ }^{18}$. The presence of hydrophilic groups such as hydroxyl -OH, amine $-\mathrm{NH}_{2}$ or carboxyl units $-\mathrm{COOH}$ can change the level of water on the surface of materials. This layer of water molecules can indirectly provide a low interfacial free energy with the biological fluids and reduce the tendency of proteins to adhere to the implant. Moreover, it has been recently demonstrated that the arrangement of water molecules at the polymer interface changes according to the polymer coating and can impact the degree of protein adsorption ${ }^{19}$. Another important component is also the ability of the polymer coating to provide a certain degree of steric repulsion to limit protein adsorption. Poly(ethylenglycol) (PEG) is one such standard choice for polymer coating ${ }^{20}$. PEG chains length and conformation combined with its high degree of hydration and flexibility can create a barrier to protein adsorption ${ }^{21}$.

Considering the above mentioned fundamental aspects, the following section will discuss in detail the currently available polymer coatings and strategies to engineer bio-inert surfaces. Furthermore, specific attention will be given to surface coatings for cardiovascular implants, that aims to enhance compatibility with the blood.

\subsection{Strategies to design bio-inert polymeric coatings}

Bioinert coatings can be applied on a variety of materials including metallic, ceramic and polymeric surfaces. However, not all types of surfaces contain active and functional groups for chemical conjugation. This is the case of polymer surfaces that generally has to undergo a step of chemical pre-treatment or irradiation to be further functionalized ${ }^{22}$. Physical techniques can also be utilized for activating the surface for coupling bioinert polymers. This includes UV and gamma irradiation, electron beam, corona discharge, ion beam, laser and plasma treatment. 
UV irradiation represents a fast and low cost process that allows for photo-grafting polymeric chains on the surface of biomedical implants. The reaction is generally carried out in the presence of a biocompatible photoinitiator that can break down into radicals responsible for the surface activation. Upon formation of free radicals from the photoinitiator, vinyl monomers in the surrounding solutions will act to propagate the radical reactions leading to the formation of grafted polymer chains on the surface of the implants ${ }^{23}$. Nevertheless, one of the persisting concerns with the use of UV is that the process may not only alter the surface of the implant but also its bulk properties. In fact, if the material becomes too stiff after UV exposure, the risk of thrombosis in the case of cardiovascular implants such as synthetic vascular graft can dramatically increase ${ }^{24}$. This problem can be overcome by using short wavelength radiation in the extreme ultraviolet region (EUV) that would result in the modification of a very thin layer $(<100 \mu \mathrm{m})$ of the medical device. Thus, allowing for surface modification without inducing changes to the bulk.

An alternate strategy to introduce reactive sites on the material surfaces would be to employ plasma treatment. In this approach, the biomaterial surface is exposed to high energy radiation consisting of atoms, molecules, ions and radicals generated by gaseous mixture $\left(\mathrm{CO}_{2}, \mathrm{O}_{2}, \mathrm{~N}_{2}, \mathrm{NH}_{3}\right.$, and $\left.\mathrm{H}_{2}\right)$, vacuum arc or a laser source ${ }^{25}, 26$. This technique can specifically modify hydrophilicity, roughness as well as the chemical composition without changing the bulk properties of medical devices.

Once the required functionality has been introduced on the implant surface following the possible strategies above described, multiple methodologies can be pursued to apply the desired polymeric coating. The type of coating can be chosen considering several parameters including the anchoring site, polymer topology and steric effect that can influence its stability. Self assembly, non covalent physisorption and covalent binding of polymer brushes represent some of the well-established strategies to generate polymeric bioinert coatings. A brief description of these techniques will be provided in the following subsections.

\subsubsection{Self-assembly monolayers (SAMs) and physisorptions of polymeric multilayers-Self-assembly monolayers (SAMs) can be considered as molecular} assemblies that are generally created by the spontaneous adsorption of organic molecules on a solid surface such as metal implants ${ }^{27}$. In general, molecules used to obtain SAM consist of three parts: a head anchor group (such as thiol, silane, phosphate and cathecol), an alkyl chain and functionalized end regions ${ }^{28}$. The head anchor has to provide a stable attachment of the coating to the surface and usually the ones having multifunctional groups represent a better option to achieve an increased stability of the coating ${ }^{29}$ (Fig 1a).

These monolayers generate homogeneous structures with high stability due to strong interchain interactions that can affect surface wettability and friction. However, one of the disadvantage of SAM technique is that it is not possible to obtain dense coating on the surface of bioimplant due to steric effect that can limit the corresponding "anti-biofouling" activity.

Another possibility is represented by physical adsorption on chemically inert polymeric surfaces. Such anti-fouling coatings are usually made of amphiphilic block copolymers like 
poly (ethylene glycol)-b-poly(propyleneoxide) PEG-PPO, poly(llysine)-b-poly(ethylene glycol) PLL-PEG, that are adsorbed through hydrophobic or electrostatic interactions respectively ${ }^{30,31}$. In contrast to a single layer, multilayers of physically adsorbed polymers offer a better control over the thickness of the coating and pose as a useful strategy to obtain a higher surface coverage. Moreover the presence of possible hydrophilic, hydrophobic or covalent crosslinking during multilayer formation can increase the general stability of the coating $^{32,33}$ (Fig 1b).

2.1.2 Polymeric brush coatings-Apart from physical interactions, covalent bonding of polymer brushes offers a unique platform to exert desired surface properties on implants.

Polymer brush coating present a series of advantages including the presence of multifunctional groups in the branched structure, that permit a further modification with biological molecules and also exhibits controlled swelling and wettability ${ }^{34}$. Furthermore, parameters such as molecular weight and crosslinking density can be controlled over the process of grafting, guaranteeing a defined 3D architecture. Specifically, densely grafted polymeric brush can act as barrier to limit undesired interactions between the surface of the implants and the immunological components. "Grafting to" and "grafting from" are the two distinct approaches used for the preparation of polymer brush coatings ${ }^{34,35}$ (Fig 1c).

The former involves a reaction of pre-functionalized polymers with a surface that contains the necessary complementary groups. This approach cannot produce high grafting density as the presence of previously included polymeric chains can hamper the introduction of new ones $^{36}$. Due to this limitation, the latter "grafting from" strategy embodies the most attractive strategy for the preparation of brush coatings. Particularly, it involves the immobilization of specific initiators on the surface of biomaterials that starts the process of monomer polymerization. "Grafting from" can allow for a higher graft density that is mainly regulated by the initiator density on the material surface. Nevertheless, low initiator efficiency and variable diffusion of the monomer to the active polymerization site are some of the persisting drawback of this technique ${ }^{37,38}$. These limitations usually results in the formation of brushed coating with a broader chain length distribution respect to SAM. "Grafting from" can be applied on both organic and inorganic surfaces and this process of brush polymer formation can be obtained following several methods such as atom transfer radical polymerization (ATRP), initiator transfer terminator polymerization (INIFERTER) and reversible addition fragmentation chain transfer (RAFT) ${ }^{39-41}$. Different type of polymer brushes can be produced using these techniques including neutral, zwitterionic, homo and block-co-polymer ${ }^{44,45}$. All the proposed approaches so far can be chosen according to the material surface and the type of biomedical implant designed for a particular application. Moving further, state-of-the-art techniques for modulating cardiovascular implant surfaces to prevent undesired host responses such as thrombogenesis and inflammatory responses will be discussed.

\subsection{Bioinert surfaces for cardiovascular implants}

One of the main obstacles that we still need to overcome while developing cardiovascular implants is their compatibility when exposed to blood ${ }^{42}$. Specifically, it is desirable to obtain surface properties that can avoid thrombogenesis, the major concern for vascular 
grafts, stents and heart valves. This can be achieved by preventing platelet adhesion and activation, hence reducing the chance of thrombosis. As discussed above, a possible approach to achieve this goal can be the formation of anti-fouling polymer coatings on the surface of medical devices. Interesting examples of this include hydrophilic neutral coatings that can impart protein resistance to a surface with the help of $\mathrm{PEG}^{43}$ and oligo ethylene glycol (OEG) ${ }^{44}$ polymers. These polymers have been easily grafted on Nitinol stents, Dacron, expanded polytetrafluoroethylene (ePTFE) and polyurethane (PU) heart valves ${ }^{45}$. A detailed analysis of chemical strategies using PEG and its derivates as polymer brush coating has been reported elsewhere ${ }^{46}$. Apart from PEG and OEG that exhibit excellent antifouling properties to a wide variety of proteins, other synthetic polymers generally defined as poly(2-oxazoline)s (POXs) such as poly(2-methyl-2-oxazoline) (PMeOX), poly(2-ethyl-2oxazoline) (PEtOX), and polypropyloxazoline are promising starting material for the preparation of amphiphilic coatings with similar properties of $\mathrm{PEG}^{47,48}$. At the same time zwitterionic polymer brush coatings are another emerging class of anti-fouling coatings that possess positive and negative charges in equal number. Because of their presence, these coatings are highly hydrated inducing extremely limited protein adsorption.

An interesting example is represented by phosphorylcholine (PC)-based polymers brushes such as 2-methacryloyloxyethyl phosphorylcholine (MPC) $)^{49,50}$ that mimic the property of $\mathrm{PC}$, a phospholipid found in the cell membrane, that is capable of preventing proteins and platelet adhesion. MPC coatings have been used to cover ePTFE vascular grafts and stents surfaces to increase their blood biocompatiblity ${ }^{51}$. Sulfobetaine $(\mathrm{SB})^{52,53}$ and carboxybetaine (CB) derivates ${ }^{54}$ are other emerging classes of zwitterionic polymer brushes that are potentially useful as coating to prevent platelet adhesion. Apart from polymer coatings, an alternate way of addressing this problem could be covering the surface of implants with passive coatings made of less inflammatory proteins such as haemoglobin or albumin. However, this approach is not much reliable as pre-absorbed proteins can undergo passive exchange and displacement with the ones present in plasma such as fibrinogen ${ }^{55}$.

These examples highlight the importance of passive coatings, trying to avoid or minimize the contact with the biological components of blood. However, the presence of bioactive functional groups in their external layer can pave the way for further modifications including entrapment of drugs and small biological cues. This concept has been widely investigated in the cardiovascular field in order to come up with interesting and smart designs that can play a direct role in controlling the host response.

\subsection{Bioactive surfaces for cardiovascular implants}

Bioactive coating can be a highly useful technology for cardiovascular applications, particularly to reduce adverse biological reactions such as thrombosis and inflammation. The innovative solutions proposed for these two important aspects will be briefly described in the following two sections.

\subsubsection{Antithrombotic surfaces for cardiovascular implants-To restrict} thrombosis, two different bioactive coatings can be utilized including anticoagulant and fibrinolytic interfaces. In the first case, surfaces of biomedical implants should be modified 
in order to include biological molecule capable of minimize thrombin formation. Thrombin is the key enzyme involved in blood coagulation and in this sense immobilizing heparin on the surface of implants could represent a solution. Heparin is a natural polysaccharide capable of binding antithrombin (AT-III) and forming a complex that is responsible for the inhibition of thrombin ${ }^{56}$. Heparin can be immobilized using physical adsorption through ionic bonding. In this case, heparin can be absorbed via electrostatic interaction in the presence of cationic agents such as benzalkonium chloride or tridodecylmethylammonium chloride (TDMAC) ${ }^{57}$. In a one year long study, vascular grafts made of heparin-ePFTE were found to provide resistance to thrombosis and significantly reduced early graft failure ${ }^{58}$. Additionally, the stability of heparin coatings can be enhanced using covalent grafting strategies that can be realized through cross-linking reactions involving one of the several functional groups present in heparin chain such as hydroxyls, carboxylic, or amines functionalities. However, it is essential that after grafting the biological activity of heparin is preserved. Polymer brushes made of poly(oligo(ethylene glycol) methyl ether methacrylate) (POEGMA) ${ }^{59}$ and diblock polymer POEGMA-b-poly(N-hydroxysuccinimidyl methacrylate) (PNHSMA ${ }^{60}$ were used to covalently link heparin, combining in the same system antifouling properties and the inhibition of thrombin. Table 1 summarizes a brief list of recent examples of heparin based coatings.

Despite its importance as coating for blood-contacting devices, heparin immobilization have a few side effects including osteopenia and thrombocytopenia. Moreover, the ability of heparin to bind various bioactive molecules such as growth factors and plasma proteins could determine inflammatory responses caused by heparin itself or the polymer coating used $^{61}$. For this reason other inhibitors has been explored as potential candidates to hinder thrombin activity or its production. Hirudin, a potent natural inhibitor of thrombin, has been covalently grafted to several materials in cardiovascular tissue engineering application. As for heparin, chemical conjugation can alter the bioactivity of hirudin and selective attachment using the $\mathcal{E}$-ammino groups of Lys instead of the $\mathrm{N}$-terminus were found to preserve the inhibitor activity against thrombin ${ }^{62}$. Hashi et al. has recently used PEG as a spacer to covalently link the C-terminus of r-hirudin to a biodegradable small-diameter microfibrous vascular graft fabricated using electrospun poly (L-lactide) (PLLA) ${ }^{63}$. The hirudin coating caused a reduction in adherent and activated platelets on the vascular graft and increased patency six months after implantation into rat carotid arteries.

Covalent conjugation of others thrombin inhibitors has been tested. For example Yang et al. have tried to conjugate bivalirudin on plasma polymerized allylamine coated 316L stainless steel. The presence of bivalirudin was able to prolong clotting time, limiting adhesion and activation of platelets and fibrinogen. Moreover, in vivo studies indicated that thrombus formation was reduced by a rapid growth of intact endothelia on the bivalirudin-coated surface $^{64}$. Another possible strategy to create bioactive coating with anticoagulant properties is to bind on the surface nitric oxide (NO). In fact NO can limit platelet adhesion and thrombus formation on the surfaces of cardiovascular implants ${ }^{65}$. Several NO-donor compounds can be chosen modulating the rate and mechanism of NO release. Covalent grafting to pendant groups is the most common strategy to include NO-releasing compounds. A particular class of $\mathrm{NO}$ donors are diazeniumdiolates that can be linked to different polymer such as polyvinyl chloride (PVC), PU or ePTFE vascular grafts ${ }^{66,67}$. In 
addition to limiting platelet adhesion, NO-coatings can guarantee a reduction in smooth muscle cell proliferation and promote endothelial cell proliferation that can be extremely important in defining long-term patency of vascular grafts ${ }^{66}$.

As mentioned above, an alternate way to improve blood biocompatibility of medical implants for cardiovascular applications is to produce fibrinolytic surfaces. In this case, the coating should be able to local activate the endogenous fibrinolytic system reducing the formation of thrombus. One of the main strategies to achieve this goal has been reported by the intrdocution of lysing groups on the surface that present high affinity for plasminogen a key factor in the fibrinolytic system ${ }^{68}$. Chen et al. have proposed PU modification with polymer brush made of lysine-poly(2-hydroxyethyl methacrylate) Lys-(PHEMA) which is able to bind selectively plasminogen capable of causing rapid clot lysis on the surface ${ }^{69}$. Similarly, in another study, poly(OEGMA-co-HEMA) copolymers grafted on polyurethane surface were further functionalized with lysine groups showing selective binding of plasminogen and low adsorption of fibrinogen and other plasmatic proteins ${ }^{70}$.

\subsubsection{Bioactive surfaces to control immune response in cardiovascular}

implants-Bioactive coatings for cardiovascular implants surfaces should be also designed taking in consideration the immune response. In fact, the interaction between the immune and coagulation systems can profoundly affect the fate of implanted biomaterials ${ }^{71}$. An important aspect to consider is the suppression of complement activation and its fixation on the surface of medical devices ${ }^{72}$. To obtain this control over the immune responses, bioactive coatings should be able to suppress the immune response once implanted in vivo along with their antithrombotic properties. This can be achieved by grafting in the polymeric coatings bioactive molecules such as growth factors or specific receptor and antibodies. For example factor $\mathrm{H}$ a protein present in serum can inhibit complement activation and has been used as a strategy to control the complement inflammatory response ${ }^{73}$.

In an interesting study, Andersson et al. created a hybrid surface in which the anticoagulation properties were combined with a specific complement-inhibitory effect due to the presence of factor $\mathrm{H}^{74}$. In specific Pluronic ${ }^{\mathrm{TM}}$, a class of triblock copolymers consisting of a block of polypropylene oxide (PPO) surrounded on each side by polyethylene oxide (PEO) blocks was chemical conjugated with factor $\mathrm{H}$ and tested with human serum showing promising results in terms of reducing complement inflammatory cascade. Alternatively, to chemical strategies that can be costly another possible solution is to bind on the surface peptides that show high affinity for factor $\mathrm{H}$. In another study, Lambris et al. have identified a specific peptide (5C6) capable of specifically capture factor $\mathrm{H}$ without altering its functional activity ${ }^{75}$. At the same time, it is even possible to consider the possibility to bind on the surface receptor or biological proteins to reduce cell inflammatory adhesion. CD47 is a ubiquitously expressed trans-membrane protein that functions as a biological marker of self- recognition and showing the ability to C-influence inflammatory cell attachment. In a recent study, recombinant $\mathrm{CD} 47$ was modified with a poly-lysine tag to the terminus and covalently linked to polyvinyl chloride (PVC) surfaces. PVC modified with CD47 was able to inhibit both platelets and neutrophils adhesion ${ }^{81}$. Other interesting examples report instead the immobilization of the human complement receptor 1 (sCR1), that is another important inhibitor of the classical and alternative complement activation pathways ${ }^{82,83}$. 


\subsection{Bio-mimetic surfaces for cardiovascular implants}

The polymeric coatings discussed so far presents well-grounded solutions to design advanced blood-compatible material surfaces. However, concerns arise when these coatings are checked in vivo as they can be susceptible of cracking and wear leading to undesired host responses such as thrombosis, microembolism and late inflammation reactions ${ }^{84,85}$.

For this reason, researchers have started to explore other avenues including the possibility to create bio-mimetic surfaces using endothelial cells (EC). It is well known that EC can play an important role to regulate coagulation, and prevent platelet adhesion and activation ${ }^{86}$. In fact, they can secrete NO that promotes vasodilatation and inhibits clot formation ${ }^{87}$. In addition, ECs can induce fibrinolysis by secreting tissue plasminogen activator to dissolve fibrin clots and thrombomodulin to inhibit the coagulation cascade. For these reasons, strategies are aimed to include a layer of EC on the outer surface of cardiovascular implants. These may be achieved by two different approaches; one can be to implant EC coated medical devices and other one can be to promote in situ endothelialization by exploiting the innate angiogenesis system. In the case of engineered vascular grafts it is important to consider that EC should form a confluent and continuous surface with tight adherent junctions. The integrity of these junctions is important as a disruption of this layer can cause exposure of the sub-endothelial tissue matrix inducing platelet activation and aggregation ${ }^{88}$.

Complete endothelial coverage of the surface of cardiovascular devices is fundamental to avoid thrombogenesis post implantation. In order to achieve this goal, it is necessary to modulate the surface properties of cardiovascular implants to increase EC attachment. This can be made possible by working on physical cues such as microtopography ${ }^{89}$ and nanotopography ${ }^{90}$ of the medical device, particularly in the case of metal stents. In fact, topographical cues can modulate not only cell attachment but also morphology and cellular behaviour. Particulary, it exherts a profound effect on the process of endothelialization. Inclusion of cell adhesive peptides derived from the extracellular matrix demonstrates another possible solution to enhance cell adhesion and migration on implant surface ${ }^{91,92}$. However, an important thing to consider while biofunctionalizing the outer surface of the implant is that the affinity of these adhesive peptides can not only promote EC proliferation, but also can induce platelet adhesion, thus eventually making it thrombogenic ${ }^{93}$. It is thus critical to confirm the stability and nature of the adhering cells once the medical device is implanted in vivo. In particular, the endothelial monolayer should be able to sustain the surface shear stress caused by blood flow. For example, in prosthetic heart valves the surface shear stress can exceed $500 \mathrm{dyn} / \mathrm{cm}^{2}$ which is much higher than what EC can withstand ${ }^{94}$. In a recent study, Frendl et al. emphasized that endothelial adhesion is not alone sufficient to withstand ultra-high shear stress environment regardless of the adhesive nature, type and concentration of the ligand used on pyrolitic carbon surfaces. This problem was overcome by producing microfabricated trenches on the pyrolitic carbon surfaces that allowed a sensible reduction on the value of shear stress detected by cells, that retained their confluent monolayer when exposed to $600 \mathrm{dyn} / \mathrm{cm}^{2}$ 95. This approach represents an important advance in the design of biomimetic surfaces that can retain the monolayer of endothelial cells intact when exposed to higher shear stress (Fig 2). 
As an alternative to EC, endothelial progenitor cells (EPCs) that are able to differentiate into functional EC, represent another interesting cell source to promote medical device-based endothelialization ${ }^{96}$. Interestingly, synthetic materials can be coated with specific molecules such as antibodies ${ }^{97,98}$, growth factors ${ }^{99-101}$ genes $^{102,103}$ and aptamers ${ }^{104}$ to recruit circulating EPCs and generate an autologous endothelium surface.

\section{Designing biointeractive coatings to support implant integration in bone}

In previous sections, we have discussed the different strategies to suppress adverse host immune responses and increase blood biocompatibility of medical implants. However, these strategies hold limitations when considering prosthesis that have to undergo a process of remodelling to restore functionality of damaged tissues. For example, bone grafts made of polymeric materials should be able to integrate with the host and guide formation of new bone ${ }^{105}$. For such applications, several physical cues such as porosity, roughness, topography and chemical conjugation of growth factors needs to be considered to promote bone healing. A lot of effort has been made to design new surfaces and interactive coatings for orthopaedic implants to promote osseointegration. Moreover, surfaces of orthopaedic implants can also be tailored to modulate the immune responses rather than to simply suppress it. In fact, the healing process as well as the integration of the medical device within the bone tissue can be actively controlled by the immune system. This new area of research interest is defined as osteo-immune modulation. Although still in its early stage of development this area of research is progressively gaining importance due to the increased understanding of the complex cellular and molecular interactions between the immune and skeletal systems ${ }^{106}$.

The following section explores in details the new types of interactive coatings developed for metal and polymer implant-based bone regeneration. In addition, the design of recent immune-modulatory strategies for bone osseointegration will be articulated in an attempt to provide new insights on advanced materials for bone therapy.

\subsection{Surface modification with bioactive materials to promote osseointegration}

Orthopedic implants such as joint prostheses, plates and screws serve the purpose of providing mechanical and structural support to the damaged area. In addition, they should enhance healing and easily integrate with the surrounding host tissue. Among the materials used metal represent the first choice when mechanical and structural support is essential and some examples of recent strategies to modify the surface of metal orthopaedic implants are reported in Table 2.

One of the widely used approaches is to change the surface properties working on the topographical characteristics of the implants or by introducing specific functional groups. Regarding for example metal implants, an increase in surface roughness can increase the surface area leading to osteoblast differentiation with higher expression of alkaline phosphatase (ALP) and osteocalcin expression respect to smooth surfaces ${ }^{107}$. Moreover, the presence of $\mathrm{NH}_{2}$ or $\mathrm{OH}$ groups can increase the wettability improving cell attachment in vitro on titanium implants ${ }^{108}$. It has also been investigated how the type of functional group can actually influence the conformation of the adsorbed proteins such as fibronectin. The 
different active conformation of fibronectin can influence the type of integrin used for osteoblast attachment and indirectly influence the relative differentiation ${ }^{109}$.

Another possible way to enhance osseointegration can be the deposition on the surface of biomaterials that can mimic the chemical composition of natural bone. In this category, it is possible to include calcium phosphate (CaP) like coatings such as hydroxyapatite (HA). HA coatings can be introduced following several techniques including pulse layer deposition and electrostatic multilayer assemblies using the layer-by-layer technique. These coatings have been widely investigated not only for their osteoinductive properties but also for their potential use as carriers of growth factors, bioactive molecules, and $\mathrm{DNA}^{110}$. In a study by He et al., hydroxyapatite (HA)/collagen coatings were used as carrier of recombinant human bone morphogenetic protein-2 (rhBMP-2) and RGD peptide (RGD). The results showed significant improvement in mesenchymal stem cell (MSC) adhesion, proliferation, and differentiation on collagen-modified HA coatings that can be potentially used for early fixation of bone implants ${ }^{15}$. Similarly, in a recent study hydroxyapatite nanoparticles were complexed with chitosan to design nanoscale non-degradable electrostatic multilayers. These were then linked with a degradable poly ( $\beta$-amino ester) based film having physiological amounts of rhBMP-2 to form an osteoinductive coating for MSC ${ }^{111}$. Still concerns related to the efficacy ${ }^{112}$ and safety of HA coatings are yet to be overcome mainly due to their possible fragmentation in vivo ${ }^{113}$ that is responsible for inflammation, delay in osseointagration and osteolisis. This problem can be addressed by reducing thickness of the coating as well as by increasing their homogeneity ${ }^{114}$.

Other possible coatings to promote osseointegration are the ones made of silicate-based bioceramic that are generally applied using plasma spray methods, showing higher bonding strength to titanium implants respect to HA coatings ${ }^{119}$. This aspect is important as poor binding could lead to detachment of the coating from the titanium implants limiting their long-term stability once implanted in vivo. However, silicate based materials such as $\mathrm{CaSiO}_{3}$ present high dissolution rate in biological fluids and attempt has been made to increase their chemical stability by incorporating $\mathrm{Zn}$ ions in their structure ${ }^{120}$.

A possible alternative to $\mathrm{CaP}$ and silicate coatings is the fixation of bioadhesive coatings on the implants surfaces by entrapping or adsorbing ECM proteins, peptides ${ }^{121}$, growth factor $^{122}$ or DNA ${ }^{123}$. To achieve these objectives several available techniques can be considered including immobilization, hydrogels and layer-by-layer coatings. Immobilizations of peptides that contain cell binding domains represent one of the most investigated strategies to improve osseointegration in orthopaedic implants. Such peptides are more stable than large proteins and are able to withstand harsh treatments without losing their biological activity ${ }^{124}$. Among them, the ones containing RGD sequences have been largely investigated, however their lack of selectivity in integrins binding reduce their potentiality as enhancer of osseointegration ${ }^{125}$. To achieve better results different peptides displaying a more selective integrin binding have been proposed as alternative to the RGD sequence ${ }^{126}$. For instance, titanium implants have been coated with a triple helical peptide, GFOGER derived from $a_{1}$ (I) chain of type I collagen that has specific affinity for integrin $a_{2} \beta_{1}$. The Ti surfaces treated with the peptide showed higher ALP activity and calcium content compared to the ones uncoated ${ }^{127}$. 
Immobilization can be extended not only to peptides but also to cytokines and growth factors although their biological activity can be reduced after this process. For this reason in general it is necessary to introduce a layer on the implant surface that can be used to link the growth factor. Kashiwagi et al. reported the formation of a bioactive layer of artificial protein on titanium surface with the help of titanium binding motifs fused to the N-terminal of BMP-2 ${ }^{128}$. In a similar study Naskar et al. immobilized silk fibroins on titanium surface to facilitate the initial cell adhesion followed by improved cell spreading and better mineralization in order to achieve enhanced osseointegration. The immunological responses along with the effect of cytokines on osteoblast adhesion and function were investigated showing that the silk fibroin from non-mulberry source could be potentially used for better osteogenesis on orthopedic implants ${ }^{129}$. Apart from immobilization of adhesive proteins or peptides, polymeric hydrogels can be an alternative method to coat orthopaedic implants with bioactive molecules. A gel layer can be simply obtained by soaking the orthopaedic device into polymeric solutions that contain the biomolecule of interest prior hydrogel formation. This simple technique can be applied to coat implant with complex geometry although this method cannot be considered reproducible as variability can occur from batch to batch. In a study by Stadlinger et al., various hydrogels were tested as coating of titanium implants loaded with TGF- $\beta 1 /$ BMP-4 growth factors using collagen, decorin and chondroitin sulphate. The results indicate that a collagen/chon- droitin sulphate coating was the most effective among the tested hydrogels in promoting osseointegration ${ }^{130}$.

Layer-by-layer coating is another widely used strategy. It consists of alternate repeated soaking of implants into polyelectrolyte solutions with opposite charges. This technique allows a better control over the loading efficiency and the release kinetics of the entrapped biomolecule respect to hydrogel coatings. In fact, several important parameters can be chosen such as the number of layers, type of polyelectolyte and the concentration of the biomolecule. The layer-by-layer approach have been studied Macdonald et al. to promote delivery of different growth factors such as VEGF and BMP-2 ${ }^{122,131}$ (Fig 3). Here, a layer by layer coating was used as carrier for the dual release of rhBMP-2 and rhVEGF $_{165}$. The first one was released over a period of 2 weeks, while rhVEGF $_{165}$ eluted from the film over the first 8 days. The sequential delivery of growth factors has been used to target both blood vessel formation and bone formation. Most importantly, both growth factors retained their efficacy and an improvement in bone formation was observed compared to the system with the delivery of only one growth factor ${ }^{132}$.

\subsection{Surface modification with osteoimmunomodulating factors to promote osseointegration}

The immune and the skeletal system share several regulatory pathways. Extensive research over the last two decades has demonstrated the influence of the immune system on the regulation over bone healing ${ }^{106,133}$. This important cross-talk among the two systems could be a useful tool for the design of a new generation of "immuno-informed" biomaterials capable of positively interact with the immune system rather than trying to dampen its effect. In fact, the innate immune system can play an important role in bone repair and maintaining its homeostasis. Among the cells of the innate immunity, macrophages have been identified as key elements for bone repair ${ }^{134}$. According to the micro-environment, macrophages can 
display different polarization states into the pro-inflammatory M1 type and the antiinflammatory M2 type. M2 population can be further subdivided into M2a (antiinflammatory), M2b (immune-regulatory) and M2c (remodelling) mainly due to their surface receptor expression and cytokine secretory profile ${ }^{4}$. However, there is plasticity among macrophage phenotypes, meaning that they possess a continuum of phenotypes for distinct biological functions.

Macrophage polarization can be influenced by biochemical and biophysical cues that are more inherently to the material properties of the surface of the implants. In fact, macrophages rely for their migratory, phagocytic and mechano-sensing activities mainly on short lived focal complexes, point contacts and podosomes ${ }^{135}$. In this regard, topographical cues including surface roughness, specific surface area, scale and shape of the feature ${ }^{35}$ represent example of biophysical parameters that can be finely tuned to control macrophage cytoskeleton mediated mechanisms and influencing their response in bone healing. A lot of studies have been oriented in understanding the relation between macrophage phenotype and topographical cues of biomaterial surfaces ${ }^{136,137}$. For example, Chen et al. found out that surface with $1 \mu \mathrm{m}$ wide gratings showed the lowest inflammatory response compared to nanogratings and planar controls ${ }^{137}$ (Fig 4). Same results were confirmed in other studies where topographical features of different polymeric microfibers in the range of 1 to $5 \mu \mathrm{m}$ showed well acceptance after implantation in vivo respect to other with higher gratings ${ }^{138}$.

Apart from topographical characteristics, also mechanical properties can profoundly influence macrophage phenotype ${ }^{139}$. In fact, macrophage elasticity can be modified by the substrate stiffness. For example Blakney et al. showed that hydrogel stiffness did not impact macrophage attachment, but was able to influence their morphology and corresponding phenotype. In fact, hydrogels with lower stiffness led to reduced macrophage activation and a less expression of TNF- $a$, IL- $1 \beta$, and IL- $6^{140}$. Considering all these factors to design better orthopaedic implants, scientists are now trying to decipher all the unique surface properties that control macrophage polarization in an attempt to enhance the process of osseointegration. For instance, titanium topography of orthopaedic implants is one of the factors that has been an object of intense research over the years. In a recent study by CalvoGuirado et al., biomechanical comparison of bone response to commercially pure titanium screws with four different types of surface topographies was investigated. In specific, the surface of the titanium implants were sandblasted, acid-etched or treated with a combination of the two techniques along with a four group in which also a discrete crystal deposition (DCD) of HA was applied. Implants were placed in the tibial metaphysis of 30 rabbits and this study indicated that only titanium with increased surface roughness showed statistically significant increase in osseointegration, 56 days after implantation ${ }^{141}$. Apart from conventional HA coatings used in the previous study, ceramic containing bioactive elements such as $\mathrm{Mg}, \mathrm{Si}$ and $\mathrm{Sr}$ have also been proved to have immunomodulatory effects that can enhance in vivo osteogenesis. For example clinoenstatite coatings $\left(\mathrm{MgSiO}_{3}\right)$ or bioactive ceramic having $\mathrm{Mg}, \mathrm{Si}$ and $\mathrm{Sr}\left(\mathrm{Sr}_{2} \mathrm{MgSi}_{2} \mathrm{O}_{7}\right)$ are capable of controlling macrophage differentiation into the M2 lineage while inhibiting inflammation and osteoclastic activity $^{142,143}$. Similarly, titanium surface hydrophilicity has been proven to accelerate implant osseointegration in humans ${ }^{144}$. In a recent study, the mechanism behind this modulatory effect has been further investigated by evaluating the inflammatory cytokine 
expression profile in a murine macrophage cell line. Results illustrated how the increased hydrophilicity can decline the pro-inflammatory response by activating NF- $\mathrm{KB}$ signalling ${ }^{145}$. Importantly, MSCs co-cultured with macrophages in 3D scaffold led to a significant decrease in the secretion of soluble factors related with inflammation and chemotaxis including IL-6 and MCP-1 compared to 2D settings ${ }^{146}$.

To further investigate the influence of macrophage over tissue remodelling, post implantation, other studies have been carried out. Brown et al. explored whether the presence of a cellular component in ECM scaffolds influence macrophage phenotype. Acellular matrices were shown to elicit a predominantly M2 type response and resulted in constructive remodelling, while those containing a cellular component presented M1 polarization response leading to deposition of dense connective tissue and scarring ${ }^{147}$. Very recently, a novel approach to assess osteogenesis in vitro has been proposed by Chen et $a l^{148}$. In their study the osteogenic capacity of cobalt incorporated with $\beta$-tricalcium phosphate (TCP) was assessed using a coculture of MSCs and macrophages and compared with the traditional "one cell type" method. Macrophage phenotype switched to M1 in response to TCP. The group also performed in vivo studies to support their in vitro findings. This study represents an important example that combines both immune and skeletal system together and represents a smart approach for in vitro testing of ortheopedic implants and predicts their behaviour once implanted in vivo.

\section{Conclusion and Future Directions}

To conclude, the review highlights the currently available strategies to control the surface properties of biomedical implants for cardiovascular and bone therapy applications and possible solutions to control the adverse host responses. Emerging approaches to control host immune responses against the foreign medical implants using bioactive molecules and polymers are also underscored. It can be stated without any reservation that significant advancements have been made in developing different types of bioinert surfaces to prevent non specific protein adsorption. With respect areas where we still need to improve is to close the gap between in vitro and in vivo study outcomes. The main cause for this mismatch with respect to cardiovascular implants is probably due to the incomplete understanding of the specific mechanisms involved in the cross-talk between the immune system and the coagulation mechanism. A better understanding of the underlying pathways, which bridge the gap between the two systems, will significantly contribute to improve the biomaterial coating strategies, suppress thrombosis and host complement activation systems. Since thrombus formation involves several complex mechanisms, surface modifications that address only one possible way to block its formation does not present a holistic strategy to manufacture successful cardiovascular implants. It is imperative to integrate several coating strategies with complementary strengths to build smarter next-generation biomaterial-based medical implants.

In near future, strategies to engineer the ideal bioinert coatings can be harnessed from the nature considering the vast number of nonbiofouling surfaces present. In a recent study by Leslie et al., such a concept has been put forward and demonstrated by fabricating a bioinspired, omniphobic coating surface capable of repelling blood and suppressing biofilm 
formation ${ }^{149}$. To do this, a slippery liquid-infused porous surface (SLIPS) was synthesized following the Nepenthes pitcher plant's example, that uses a layer of liquid water to create a low friction surface that prevents attachment of insects. Such bioinspired materials thus signify an innovative approach that may lead to the discovery of successful coatings in the field of biomedical devices.

Our second objective was to shed lights on the current research works in the field of surface chemistry and material interfaces to control host biological responses and tissue integration. This is extremely important in case of orthopaedic implants, in which osseointegration is a necessary step to accelerate bone healing. We believe the innovative coatings illustrated in this review, particularly the ones which consider immune responses as a useful resource to promote bone healing, has immense potential for future clinical applications.

Ideally, the next generation orthopaedic implants should be able to deliver the optimal amounts of growth factors within the bone healing area while exerting a possible control over the immune responses. One possible way could be the entrapment on the surface of growth factors recruiting M1 macrophages over an initial period of time to initiate vascularization followed by the sustained release of other cytokines to recruit M2 macrophages, that will help the formation of a mature and stable vasculature. However, very little is known about the specific roles of the two macrophage phenotypes M1 and M2 in the different musculoskeletal diseases and healing phases. Growing understanding of these mechanisms to regulate macrophage polarization will help pave the way in developing more advanced orthopaedic implants with emerging surface bioengineering techniques.

Microfabricating organ-on-a-chip in vitro models capable of mimicking the cross-talk between osteoblast and macrophage could play a highly beneficial role in the advancement of these technologies.

\section{Supplementary Material}

Refer to Web version on PubMed Central for supplementary material.

\section{Acknowledgements}

Arghya Paul would like to acknowledge the Institutional Development Award (IDeA) from the National Institute of General Medical Sciences of National Institutes of Health (NIH), under Award Number P20GM103638-04 and University of Kansas New Faculty General Research Fund. Satya Prakash acknowledges the support from Canadian Institute of Health Research (CIHR) Grant (MOP 264308).

\section{References}

1. Lodder A, Kamath MV, Upton AR, Armstrong D. Journal of long-term effects of medical implants. 2010; 20:173-185. [PubMed: 21395517]

2. Anderson JM, Rodriguez A, Chang DT. Seminars in immunology. 2008; 20:86-100. [PubMed: 18162407]

3. Brodbeck WG, Anderson JM. Current opinion in hematology. 2009; 16:53-57. [PubMed: 19057205]

4. Kou PM, Babensee JE. Journal of biomedical materials research. Part A. 2011; 96:239-260. [PubMed: 21105173] 
5. Rajesh, PSM.; Verma, S.; Verma, V.; Balani, K.; Verma, V.; Agarwal, A.; Narayan, R. Biosurfaces. John Wiley \& Sons, Inc; 2015. p. 106-125.DOI: 10.1002/9781118950623.ch3

6. Ratner BD. Journal of cardiovascular translational research. 2011; 4:523-527. [PubMed: 21710333]

7. Worz A, Berchtold B, Moosmann K, Prucker O, Ruhe J. Journal of Materials Chemistry. 2012; 22:19547-19561.

8. Mokarram N, Bellamkonda RV. Annals of biomedical engineering. 2014; 42:338-351. [PubMed: 24297492]

9. Schlundt C, Schell H, Goodman S, Vunjak-Novakovic G, Duda G, Schmidt-Bleek K. J EXP ORTOP. 2015; 2:1-10.

10. Yu K, Mei Y, Hadjesfandiari N, Kizhakkedathu JN. Colloids and Surfaces B: Biointerfaces. 2014; 124:69-79. [PubMed: 25193153]

11. Rostam HM, Singh S, Vrana NE, Alexander MR, Ghaemmaghami AM. Biomaterials Science. 2015; 3:424-441. [PubMed: 26222286]

12. Anselme K, Ploux L, Ponche A. Journal of Adhesion Science and Technology. 2010; 24:831-852.

13. Franz S, Rammelt S, Scharnweber D, Simon JC. Biomaterials. 2011; 32:6692-6709. [PubMed: 21715002]

14. Morais J, Papadimitrakopoulos F, Burgess D. AAPS J. 2010; 12:188-196. [PubMed: 20143194]

15. Bryers JD, Giachelli CM, Ratner BD. Biotechnology and bioengineering. 2012; 109:1898-1911. [PubMed: 22592568]

16. Carré A, Lacarrière V. Journal of Adhesion Science and Technology. 2010; 24:815-830.

17. Arima Y, Iwata H. Biomaterials. 2007; 28:3074-3082. [PubMed: 17428532]

18. Wilson CJ, Clegg RE, Leavesley DI, Pearcy MJ. Tissue engineering. 2005; 11:1-18. [PubMed: 15738657]

19. Hirata T, Matsuno H, Kawaguchi D, Hirai T, Yamada NL, Tanaka M, Tanaka K. Langmuir : the ACS journal of surfaces and colloids. 2015; 31:3661-3667. [PubMed: 25760401]

20. Heyes CD, Groll J, Moller M, Nienhaus GU. Molecular BioSystems. 2007; 3:419-430. [PubMed: 17533455]

21. Kingshott P, Thissen H, Griesser HJ. Biomaterials. 2002; 23:2043-2056. [PubMed: 11996046]

22. Rana D, Matsuura T. Chemical Reviews. 2010; 110:2448-2471. [PubMed: 20095575]

23. Ebara M, Hoffman JM, Stayton PS, Hoffman AS. Radiation Physics and Chemistry. 2007; 76:1409-1413.

24. Ul Ahad I, Bartnik A, Fiedorowicz H, Kostecki J, Korczyc B, Ciach T, Brabazon D. Journal of Biomedical Materials Research Part A. 2014; 102:3298-3310. [PubMed: 24132935]

25. Chu PK, Chen J, Wang L, Huang N. Materials Science and Engineering: R: Reports. 2002; 36:143-206.

26. Zhao Y, Yeung KW, Chu PK. Applied Surface Science. 2014; 310:11-18.

27. Love JC, Estroff LA, Kriebel JK, Nuzzo RG, Whitesides GM. Chem Rev. 2005; 105:1103-1169. [PubMed: 15826011]

28. Wei Q, Becherer T, Angioletti-Uberti S, Dzubiella J, Wischke C, Neffe AT, Lendlein A, Ballauff M, Haag R. Angewandte Chemie International Edition. 2014; 53:8004-8031.

29. Fasting C, Schalley CA, Weber M, Seitz O, Hecht S, Koksch B, Dernedde J, Graf C, Knapp EW, Haag R. Angewandte Chemie (International ed. in English). 2012; 51:10472-10498. [PubMed: 22952048]

30. Chang Y, Chu W-L, Chen W-Y, Zheng J, Liu L, Ruaan R-C, Higuchi A. Journal of Biomedical Materials Research Part A. 2010; 93A:400-408. [PubMed: 19569222]

31. Rossetti FF, Reviakine I, Csúcs G, Assi F, Vörös J, Textor M. Biophysical Journal. 2004; 87:17111721. [PubMed: 15345550]

32. Heuberger R, Sukhorukov G, Vörös J, Textor M, Möhwald H. Advanced Functional Materials. 2005; 15:357-366.

33. Wong SY, Han L, Timachova K, Veselinovic J, Hyder MN, Ortiz C, Klibanov AM, Hammond PT. Biomacromolecules. 2012; 13:719-726. [PubMed: 22300304] 
34. Moroni L, Klein Gunnewiek M, Benetti EM. Acta biomaterialia. 2014; 10:2367-2378. [PubMed: 24607856]

35. Li D, Zheng Q, Wang Y, Chen H. Polymer Chemistry. 2014; 5:14-24.

36. Brittain WJ, Minko S. Journal of Polymer Science Part A: Polymer Chemistry. 2007; 45:35053512.

37. Turgman-Cohen S, Genzer J. Journal of the American Chemical Society. 2011; 133:17567-17569. [PubMed: 21978360]

38. de Vos WM, Leermakers FAM, de Keizer A, Kleijn JM, Cohen Stuart MA. Macromolecules. 2009; 42:5881-5891.

39. Siegwart DJ, Oh JK, Matyjaszewski K. Progress in Polymer Science. 2012; 37:18-37. [PubMed: 23525884]

40. Otsu T. Journal of Polymer Science Part A: Polymer Chemistry. 2000; 38:2121-2136.

41. Chiefari J, Chong YK, Ercole F, Krstina J, Jeffery J, Le TPT, Mayadunne RTA, Meijs GF, Moad CL, Moad G, Rizzardo E, Thang SH. Macromolecules. 1998; 31:5559-5562.

42. International Journal of Biomaterials. 2012; 2012:8.

43. Lee S, Vörös J. Langmuir : the ACS journal of surfaces and colloids. 2005; 21:11957-11962. [PubMed: 16316138]

44. Kizhakkedathu JN, Janzen J, Le Y, Kainthan RK, Brooks DE. Langmuir : the ACS journal of surfaces and colloids. 2009; 25:3794-3801. [PubMed: 19708153]

45. Park K, Shim HS, Dewanjee MK, Eigler NL. Journal of biomaterials science (Polymer edition). 2000; 11:1121-1134.

46. Meyers SR, Grinstaff MW. Chem Rev. 2012; 112:1615-1632. [PubMed: 22007787]

47. Wang H, Li L, Tong Q, Yan M. ACS Applied Materials \& Interfaces. 2011; 3:3463-3471. [PubMed: 21834589]

48. Zhang N, Pompe T, Amin I, Luxenhofer R, Werner C, Jordan R. Macromolecular Bioscience. 2012; 12:926-936. [PubMed: 22610725]

49. Tateishi T, Kyomoto M, Kakinoki S, Yamaoka T, Ishihara K. Journal of Biomedical Materials Research Part A. 2014; 102:1342-1349. [PubMed: 23720384]

50. Kyomoto M, Moro T, Takatori Y, Kawaguchi H, Nakamura K, Ishihara K. Biomaterials. 2010; 31:1017-1024. [PubMed: 19906420]

51. Jordan SW, Faucher KM, Caves JM, Apkarian RP, Rele SS, Sun XL, Hanson SR, Chaikof EL. Biomaterials. 2006; 27:3473-3481. [PubMed: 16516285]

52. Yu B-Y, Zheng J, Chang Y, Sin M-C, Chang C-H, Higuchi A, Sun Y-M. Langmuir : the ACS journal of surfaces and colloids. 2014; 30:7502-7512. [PubMed: 24913288]

53. Sin MC, Sun YM, Chang Y. ACS Appl Mater Interfaces. 2014; 6:861-873. [PubMed: 24351074]

54. Keefe AJ, Brault ND, Jiang S. Biomacromolecules. 2012; 13:1683-1687. [PubMed: 22512660]

55. Geelhood SJ, Horbett TA, Ward WK, Wood MD, Quinn MJ. Journal of biomedical materials research. Part B, Applied biomaterials. 2007; 81:251-260.

56. Schenone M, Furie BC, Furie B. Current opinion in hematology. 2004; 11:272-277. [PubMed: 15314527]

57. Ritter EF, Fata MM, Rudner AM, Klitzman B. Plastic and reconstructive surgery. 1998; 101:142146. [PubMed: 9427927]

58. Bosiers M, Deloose K, Verbist J, Schroë H, Lauwers G, Lansink W, Peeters P. Journal of Vascular Surgery. 2006; 43:313-318. [PubMed: 16476607]

59. Xu FJ, Li YL, Kang ET, Neoh KG. Biomacromolecules. 2005; 6:1759-1768. [PubMed: 15877403]

60. Zhang Y, Yu Q, Huang H, Zhou F, Wu Z, Yuan L, Li D, Chen H. Soft Matter. 2010; 6:2616-2618.

61. Goodwin SC, Yoon HC, Chen G, Abdel-Sayed P, Costantino MM, Bonilla SM, Nishimura E. Cardiovascular and interventional radiology. 2003; 26:158-167. [PubMed: 12616416]

62. Lahann J, Pluster W, Klee D, Gattner HG, Hocker H. Journal of materials science. Materials in medicine. 2001; 12:807-810. [PubMed: 15348228]

63. Hashi CK, Derugin N, Janairo RR, Lee R, Schultz D, Lotz J, Li S. Arteriosclerosis, thrombosis, and vascular biology. 2010; 30:1621-1627. 
64. Yang Z, Tu Q, Maitz MF, Zhou S, Wang J, Huang N. Biomaterials. 2012; 33:7959-7971. [PubMed: 22877639]

65. Ignarro LJ, Napoli C, Loscalzo J. Circulation research. 2002; 90:21-28. [PubMed: 11786514]

66. Jun HW, Taite LJ, West JL. Biomacromolecules. 2005; 6:838-844. [PubMed: 15762649]

67. Major TC, Brant DO, Reynolds MM, Bartlett RH, Meyerhoff ME, Handa H, Annich GM. Biomaterials. 2010; 31:2736-2745. [PubMed: 20042236]

68. Tang Z, Liu X, Luan Y, Liu W, Wu Z, Li D, Chen H. Polymer Chemistry. 2013; 4:5597-5602.

69. Li D, Chen H, Wang S, Wu Z, Brash JL. Acta biomaterialia. 2011; 7:954-958. [PubMed: 20977952]

70. Wu Z, Chen H, Liu X, Brash JL. Macromolecular Bioscience. 2012; 12:126-131. [PubMed: 21998081]

71. Delvaeye M, Conway EM. Blood. 2009; 114:2367-2374. [PubMed: 19584396]

72. Nilsson B, Ekdahl KN, Mollnes TE, Lambris JD. Molecular Immunology. 2007; 44:82-94. [PubMed: 16905192]

73. Ferreira VP, Pangburn MK, Cortés C. Molecular Immunology. 2010; 47:2187-2197. [PubMed: 20580090]

74. Andersson J, Bexborn F, Klinth J, Nilsson B, Ekdahl KN. Journal of Biomedical Materials Research Part A. 2006; 76A:25-34. [PubMed: 16250010]

75. Wu YQ, Qu H, Sfyroera G, Tzekou A, Kay BK, Nilsson B, Nilsson Ekdahl K, Ricklin D, Lambris JD. Journal of immunology (Baltimore, Md. : 1950). 2011; 186:4269-4277.

76. Su L-C, Chen Y-H, Chen M-C. ACS Applied Materials \& Interfaces. 2013; 5:12944-12953. [PubMed: 24294944]

77. Zhang K, Li J-A, Deng K, Liu T, Chen J-Y, Huang N. Colloids and Surfaces B: Biointerfaces. 2013; 108:295-304. [PubMed: 23563297]

78. Yang Y, Qi P, Wen F, Li X, Xia Q, Maitz MF, Yang Z, Shen R, Tu Q, Huang N. ACS Applied Materials \& Interfaces. 2014; 6:14608-14620. [PubMed: 25105346]

79. Janairo RRR, Henry JJD, Lee BL, Hashi CK, Derugin N, Lee R, Song L. NanoBioscience, IEEE Transactions on. 2012; 11:22-27.

80. Pan C-J, Hou Y-H, Zhang B-B, Dong Y-X, Ding H-Y. Journal of Materials Chemistry B. 2014; 2:892-902.

81. Finley MJ, Rauova L, Alferiev IS, Weisel JW, Levy RJ, Stachelek SJ. Biomaterials. 2012; 33:5803-5811. [PubMed: 22613135]

82. Luan NM, Teramura Y, Iwata H. Biomaterials. 2010; 31:8847-8853. [PubMed: 20739058]

83. Luan NM, Teramura Y, Iwata H. Biomaterials. 2011; 32:6487-6492. [PubMed: 21663961]

84. Kolandaivelu K, Swaminathan R, Gibson WJ, Kolachalama VB, Nguyen-Ehrenreich KL, Giddings VL, Coleman L, Wong GK, Edelman ER. Circulation. 2011; 123:1400-1409. [PubMed: 21422389]

85. Otsuka Y, Chronos NA, Apkarian RP, Robinson KA. The Journal of invasive cardiology. 2007; 19:71-76. [PubMed: 17268041]

86. Otsuka F, Finn AV, Yazdani SK, Nakano M, Kolodgie FD, Virmani R. Nature reviews. Cardiology. 2012; 9:439-453. [PubMed: 22614618]

87. Napoli C, de Nigris F, Williams-Ignarro S, Pignalosa O, Sica V, Ignarro LJ. Nitric Oxide. 2006; 15:265-279. [PubMed: 16684613]

88. Dejana E, Tournier-Lasserve E, Weinstein BM. Developmental Cell. 2009; 16:209-221. [PubMed: 19217423]

89. Lu J, Rao MP, MacDonald NC, Khang D, Webster TJ. Acta biomaterialia. 2008; 4:192-201. [PubMed: 17851147]

90. Liliensiek SJ, Wood JA, Yong J, Auerbach R, Nealey PF, Murphy CJ. Biomaterials. 2010; 31:5418-5426. [PubMed: 20400175]

91. Meyers SR, Kenan DJ, Khoo X, Grinstaff MW. Biomacromolecules. 2011; 12:533-539. [PubMed: 21218765] 
92. Meinhart JG, Schense JC, Schima H, Gorlitzer M, Hubbell JA, Deutsch M, Zilla P. Tissue engineering. 2005; 11:887-895. [PubMed: 15998228]

93. Huang G, Zhou Z, Srinivasan R, Penn MS, Kottke-Marchant K, Marchant RE, Gupta AS. Biomaterials. 2008; 29:1676-1685. [PubMed: 18192005]

94. Zhang P, Yeo JH, Qian P, Hwang NH. ASAIO journal (American Society for Artificial Internal Organs : 1992). 2007; 53:530-536. [PubMed: 17885324]

95. Frendl CM, Tucker SM, Khan NA, Esch MB, Kanduru S, Cao TM, Garcia AJ, King MR, Butcher JT. Biomaterials. 2014; 35:7714-7723. [PubMed: 24952977]

96. Yoder MC. Cold Spring Harbor Perspectives in Medicine. 2012; 2:a006692. [PubMed: 22762017]

97. Yin M, Yuan Y, Liu C, Wang J. Journal of materials science. Materials in medicine. 2009; 20:1513-1523. [PubMed: 19247584]

98. Lim WH, Seo WW, Choe W, Kang CK, Park J, Cho HJ, Kyeong S, Hur J, Yang HM, Cho HJ, Lee YS, Kim HS. Arteriosclerosis, thrombosis, and vascular biology. 2011; 31:2798-2805.

99. Shi Q, Bhattacharya V, Hong-De Wu M, Sauvage LR. Annals of vascular surgery. 2002; 16:314320. [PubMed: 11957014]

100. Stellos K, Langer H, Daub K, Schoenberger T, Gauss A, Geisler T, Bigalke B, Mueller I, Schumm M, Schaefer I, Seizer P, Kraemer BF, Siegel-Axel D, May AE, Lindemann S, Gawaz M. Circulation. 2008; 117:206-215. [PubMed: 18086932]

101. Paul A, Elias CB, Shum-Tim D, Prakash S. Scientific reports. 2013; 3:2366. [PubMed: 23917680]

102. Paul A, Shao W, Shum-Tim D, Prakash S. Biomaterials. 2012; 33:7655-7664. [PubMed: 22818986]

103. Paul A, Hasan A, Kindi HA, Gaharwar AK, Rao VT, Nikkhah M, Shin SR, Krafft D, Dokmeci MR, Shum-Tim D, Khademhosseini A. ACS nano. 2014; 8:8050-8062. [PubMed: 24988275]

104. Hoffmann J, Paul A, Harwardt M, Groll J, Reeswinkel T, Klee D, Moeller M, Fischer H, Walker T, Greiner T, Ziemer G, Wendel HP. Journal of biomedical materials research. Part A. 2008; 84:614-621. [PubMed: 17635015]

105. Ramazanoglu M, Özger Y. O. c. i. d. t. P. D. H. a. w. o. w. i. t. r. o. oncology. Osseointegration and Bioscience of Implant Surfaces - Current Concepts at Bone-Implant Interface. 2011

106. Arron JR, Choi Y. Nature. 2000; 408:535-536. [PubMed: 11117729]

107. Anselme K, Bigerelle M. Acta biomaterialia. 2005; 1:211-222. [PubMed: 16701798]

108. Rupp F, Scheideler L, Olshanska N, de Wild M, Wieland M, Geis-Gerstorfer J. Journal of Biomedical Materials Research Part A. 2006; 76A:323-334. [PubMed: 16270344]

109. Keselowsky BG, Collard DM, García AJ. Proceedings of the National Academy of Sciences. 2005; 102:5953-5957.

110. Choi S, Murphy WL. Acta biomaterialia. 2010; 6:3426-3435. [PubMed: 20304109]

111. Shah NJ, Hong J, Hyder MN, Hammond PT. Advanced materials (Deerfield Beach, Fla.). 2012; 24:1445-1450.

112. Stilling M, Rahbek O, Soballe K. Clinical orthopaedics and related research. 2009; 467:28722879. [PubMed: 19330391]

113. Furlong R. The Journal of bone and joint surgery. British volume. 1998; 80:745-746. [PubMed: 9699851]

114. Bhardwaj G, Yazici H, Webster TJ. Nanoscale. 2015; 7:8416-8427. [PubMed: 25876524]

115. Nayak S, Dey T, Naskar D, Kundu SC. Biomaterials. 2013; 34:2855-2864. [PubMed: 23357374]

116. Li JY, Pow EHN, Zheng LW, Ma L, Kwong DLW, Cheung LK. BioMed Research International. 2015; 2015:6.

117. Zhou R, Wei D, Cao J, Feng W, Cheng S, Du Q, Li B, Wang Y, Jia D, Zhou Y. ACS Applied Materials \& Interfaces. 2015; 7:8932-8941. [PubMed: 25860058]

118. Agarwal R, González-García C, Torstrick B, Guldberg RE, Salmerón-Sánchez M, García AJ. Biomaterials. 2015; 63:137-145. [PubMed: 26100343]

119. Wu C, Ramaswamy Y, Liu X, Wang G, Zreiqat H. Journal of the Royal Society, Interface / the Royal Society. 2009; 6:159-168. 
120. Li K, Yu J, Xie Y, Huang L, Ye X, Zheng X. Journal of materials science. Materials in medicine. 2011; 22:2781-2789. [PubMed: 22002471]

121. Wojtowicz AM, Shekaran A, Oest ME, Dupont KM, Templeman KL, Hutmacher DW, Guldberg RE, Garcia AJ. Biomaterials. 2010; 31:2574-2582. [PubMed: 20056517]

122. Macdonald ML, Samuel RE, Shah NJ, Padera RF, Beben YM, Hammond PT. Biomaterials. 2011; 32:1446-1453. [PubMed: 21084117]

123. Dupont KM, Boerckel JD, Stevens HY, Diab T, Kolambkar YM, Takahata M, Schwarz EM, Guldberg RE. Cell and tissue research. 2012; 347:575-588. [PubMed: 21695398]

124. Kariolis MS, Kapur S, Cochran JR. Current Opinion in Biotechnology. 2013; 24:1072-1077. [PubMed: 23587963]

125. Hennessy KM, Clem WC, Phipps MC, Sawyer AA, Shaikh FM, Bellis SL. Biomaterials. 2008; 29:3075-3083. [PubMed: 18440064]

126. Petrie TA, Raynor JE, Dumbauld DW, Lee TT, Jagtap S, Templeman KL, Collard DM, Garcia AJ. Science translational medicine. 2010:2, 45ra60.

127. Reyes CD, Petrie TA, Burns KL, Schwartz Z, García AJ. Biomaterials. 2007; 28:3228-3235. [PubMed: 17448533]

128. Kashiwagi K, Tsuji T, Shiba K. Biomaterials. 2009; 30:1166-1175. [PubMed: 19022501]

129. Naskar D, Nayak S, Dey T, Kundu SC. Scientific reports. 2014; 4:4745. [PubMed: 24752225]

130. Stadlinger B, Pilling E, Mai R, Bierbaum S, Berhardt R, Scharnweber D, Eckelt U. Journal of materials science. Materials in medicine. 2008; 19:1043-1049. [PubMed: 17701311]

131. Shah NJ, Macdonald ML, Beben YM, Padera RF, Samuel RE, Hammond PT. Biomaterials. 2011; 32:6183-6193. [PubMed: 21645919]

132. Shah NJ, Macdonald ML, Beben YM, Padera RF, Samuel RE, Hammond PT. Biomaterials. 2011; 32:6183-6193. [PubMed: 21645919]

133. Reinke S, Geissler S, Taylor WR, Schmidt-Bleek K, Juelke K, Schwachmeyer V, Dahne M, Hartwig T, Akyuz L, Meisel C, Unterwalder N, Singh NB, Reinke P, Haas NP, Volk HD, Duda GN. Science translational medicine. 2013; 5:177ra136.

134. Chazaud B. Immunobiology. 2014; 219:172-178. [PubMed: 24080029]

135. Pixley FJ. International Journal of Cell Biology. 2012; 2012:12.

136. Bota PCS, Collie AMB, Puolakkainen P, Vernon RB, Sage EH, Ratner BD, Stayton PS. Journal of Biomedical Materials Research Part A. 2010; 95A:649-657. [PubMed: 20725970]

137. Chen S, Jones JA, Xu Y, Low H-Y, Anderson JM, Leong KW. Biomaterials. 2010; 31:3479-3491. [PubMed: 20138663]

138. Sanders JE, Bale SD, Neumann T. Journal of Biomedical Materials Research. 2002; 62:222-227. [PubMed: 12209942]

139. Patel NR, Bole M, Chen C, Hardin CC, Kho AT, Mih J, Deng L, Butler J, Tschumperlin D, Fredberg JJ, Krishnan R, Koziel H. PloS one. 2012; 7:e41024. [PubMed: 23028423]

140. Blakney AK, Swartzlander MD, Bryant SJ. Journal of Biomedical Materials Research Part A. 2012; 100A:1375-1386. [PubMed: 22407522]

141. Calvo-Guirado JL, Satorres M, Negri B, Ramirez-Fernandez P, Mate-Sanchez JE, Delgado-Ruiz R, Gomez-Moreno G, Abboud M, Romanos GE. Clinical oral investigations. 2014; 18:14951505. [PubMed: 24135774]

142. Wu C, Chen Z, Wu Q, Yi D, Friis T, Zheng X, Chang J, Jiang X, Xiao Y. Biomaterials. 2015; 71:35-47. [PubMed: 26318815]

143. Wu C, Chen Z, Yi D, Chang J, Xiao Y. ACS Appl Mater Interfaces. 2014; 6:4264-4276. [PubMed: 24598408]

144. Lang NP, Salvi GE, Huynh-Ba G, Ivanovski S, Donos N, Bosshardt DD. Clinical oral implants research. 2011; 22:349-356. [PubMed: 21561476]

145. Dai X, Wei Y, Zhang X, Meng S, Mo X, Liu X, Deng X, Zhang L, Deng X. Journal of Nanomaterials. 2015; 2015:8.

146. Valles G, Bensiamar F, Crespo L, Arruebo M, Vilaboa N, Saldana L. Biomaterials. 2015; 37:124133. [PubMed: 25453943] 
147. Brown BN, Valentin JE, Stewart-Akers AM, McCabe GP, Badylak SF. Biomaterials. 2009; 30:1482-1491. [PubMed: 19121538]

148. Chen Z, Yuen J, Crawford R, Chang J, Wu C, Xiao Y. Biomaterials. 2015; 61:126-138. [PubMed: 26001077]

149. Leslie DC, Waterhouse A, Berthet JB, Valentin TM, Watters AL, Jain A, Kim P, Hatton BD, Nedder A, Donovan K, Super EH, Howell C, Johnson CP, Vu TL, Bolgen DE, Rifai S, Hansen AR, Aizenberg M, Super M, Aizenberg J, Ingber DE. Nat Biotech. 2014; 32:1134-1140. 
a
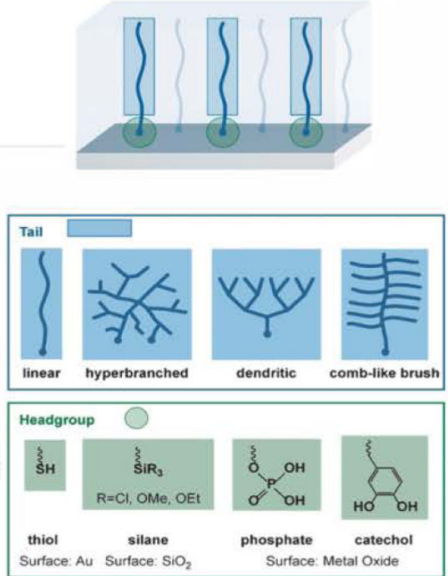

b

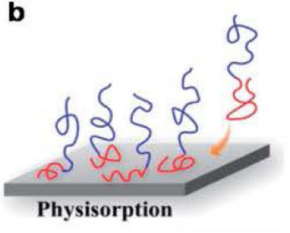

c

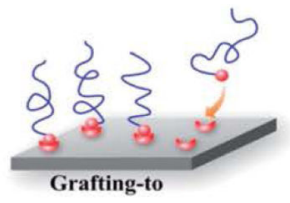

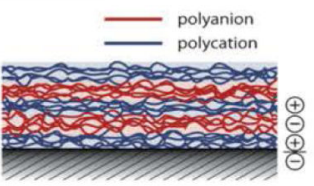
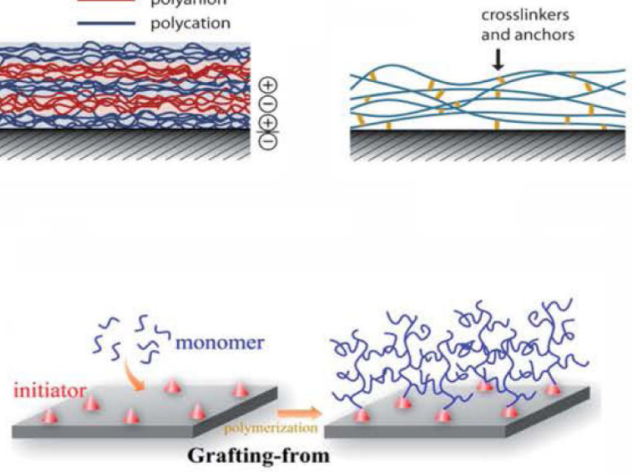

Figure 1.

Overview of available techniques for bio-inert coatings. a) Schematic of a SAM containing examples of typical head and tail domains, b) Illustration of physisorption, layer-by-layer coatings through electrostatic interaction and presence of internal crosslinking among layers to increase stability, c) grafting-to and grafting-from strategies. Reprinted with permission from 28 and 35. Copyright 2014 John Wiley and Sons and Copyright 2013 Royal Society of Chemistry. 


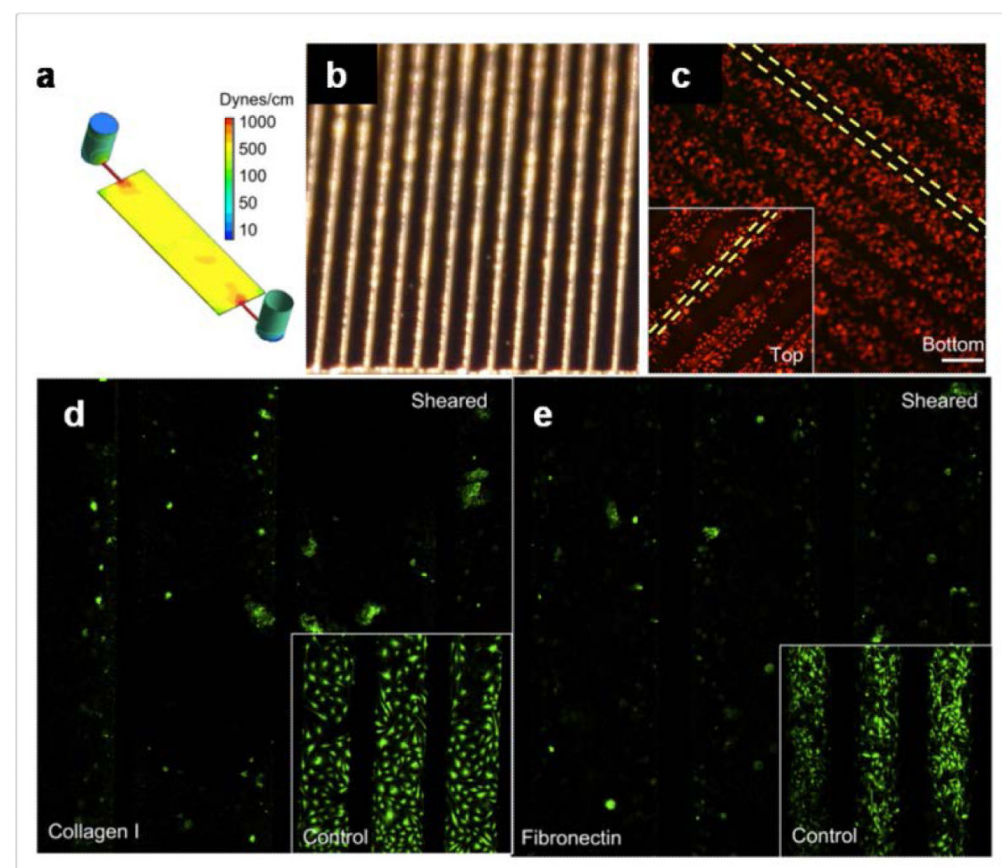

Figure 2.

Endothelialization; Micro-topographical manipulation for endothelial cell retention at high shear stress: a) Computational fluid dynamic simulation of carbonized surface channel based bioreactor under chronic ultra-high shear stress. Etched silicon channels (b) were used as a substrate for carbon deposition. c) Fluorescent image showing the retention of endothelial cells at 600 dynes $/ \mathrm{cm}^{2}$ after $48 \mathrm{~h}$ in culture, d \& e) Fluorescent images highlighting the absence of plasminogen activator inhibitor (PAI-1), an activator of fibronolysis in collagen I and fibronectin coated channels respectively under sheared and static conditions. Reprinted with permission from ref 95. Copyright 2014 Elsevier. 


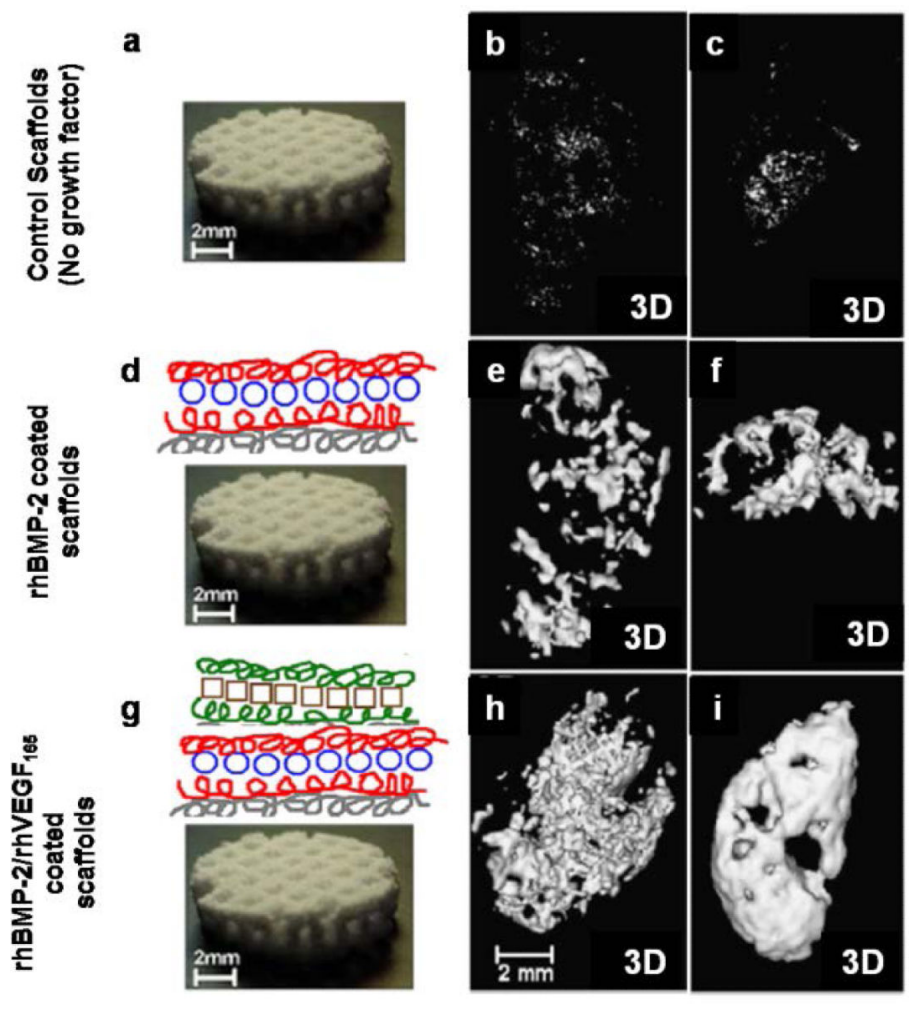

Figure 3.

Osseointegration using growth factor. a) Bare macroporous polycaprolactone/b-tricalcium phosphate (50wt\% PCL/50wt\% bTCP) waffle cylinder scaffold, with diameter of $10 \mathrm{~mm}$ and height of $2.5 \mathrm{~mm}$. b \& c) Three dimensional (3D) $\mu \mathrm{CT}$ reconstructions of intramuscular implanted scaffolds in rats. No detectable bone formation was found after 4 and 9 weeks in bare scaffolds. d) Schematic of polyelectrolyte multilayer films (PMF) using the layer-bylayer method entrapping rhBMP-2 on the surface of the scaffold. e \& f) 3D $\mu$ CT scans of scaffold with PEM releasing rhBMP-2 was able to promote bone formation only to the periphery of the scaffold. g) PEM coating containing both rhBMP-2 and rhVEGF 165. h \& i) 3D $\mu \mathrm{CT}$ scans of scaffold releasing both growth factor showed ectopically bone formation at 4 weeks with a significant increase after 9 weeks. Reprinted with permission from ref. 131 Copyright 2011 Elsevier. 


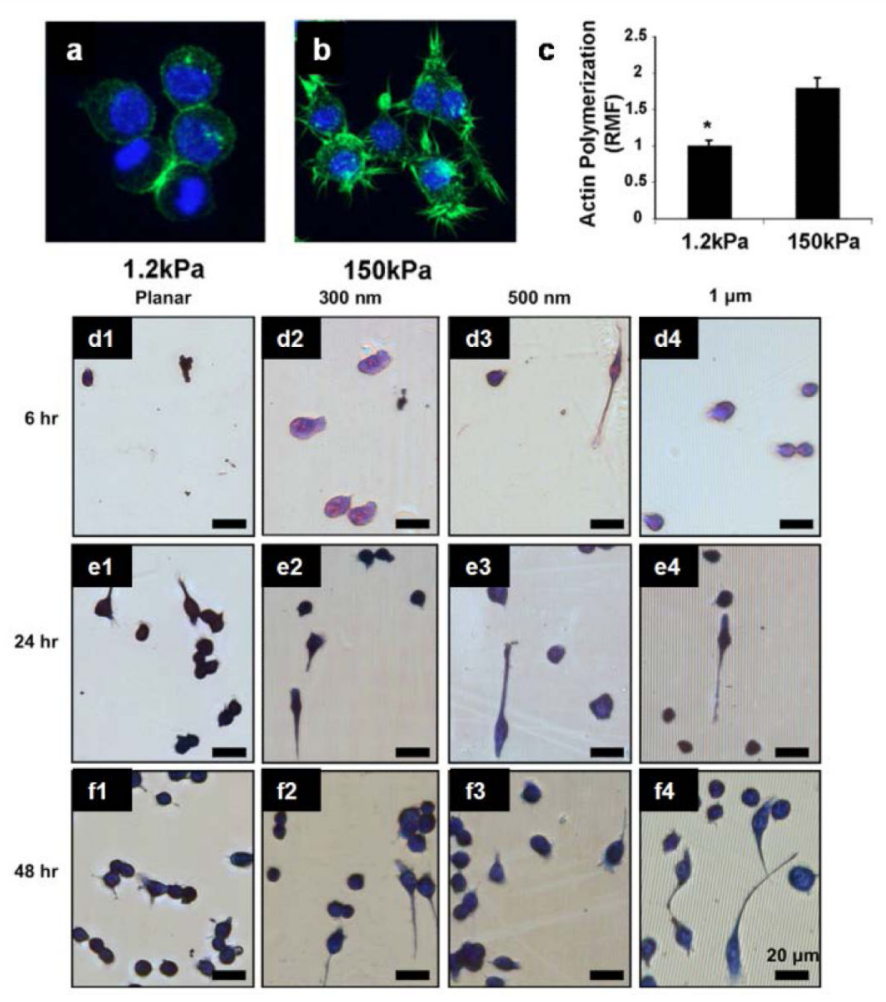

Figure 4.

Influence of elasticity and topography on macrophage polarization. a \& b) confocal images of macrophages cultured on substrate with different elasticity showing a decreased presence of filapodia in less rigid surface $(1.2 \mathrm{kPa})$. b) Quantification of actin polymerization in macrophages cultured in different elastic surfaces. d) Photomicrographs of adherent macrophage cells on PDMS gratings and controls of constant height (at $350 \mathrm{~nm}$ ): planar control (Column 1), $300 \mathrm{~nm}$ gratings (Column 2), $500 \mathrm{~nm}$ gratings (Column 3) and $1 \mathrm{~mm}$ gratings (column 4). Figure a-c reprinted with the permission from ref 139 and figure d-f from ref 137. Copyright 2010 Elsevier. 


\section{Table 1}

Innovative recent heparin based coatings for cardiovascular implants.

\begin{tabular}{|c|c|c|c|}
\hline Substrate/Coating & Coating strategy & In vitro/in vivo studies & Ref. \\
\hline Duraflo ${ }^{\mathrm{TM}}$ heparin and sirolimus & Layer-by-layer & $\begin{array}{l}\text { APTT assay, drug release studies (drug eluiting } \\
\text { stent) }\end{array}$ & 76 \\
\hline $\begin{array}{l}\text { Amino-silanized titanium/Heparin and } \\
\text { collagen Type-IV }\end{array}$ & Layer by layer & platelet adhesion test, APTT assay & 77 \\
\hline NiTi shape memory alloy/Heparin & $\begin{array}{l}\text { UV-pretreatment and physical } \\
\text { adsorption }\end{array}$ & $\begin{array}{l}\text { hemolytic tests, dynamic clotting time experiments, } \\
\text { platelet binding tests }\end{array}$ & 78 \\
\hline 316L stainless steel/heparin & $\begin{array}{l}\text { Chemical conjugation using } \\
\text { dopamine and HMA }\end{array}$ & $\begin{array}{l}\text { APTT assay, HUVECs \& HASMCs proliferation } \\
\text { studies/subcutaneous implantation in white rabbits }\end{array}$ & 78 \\
\hline Nanofibers/Heparin & $\begin{array}{l}\text { Chemical conjugation using } \\
\text { diamino-poly(ethylene glycol) as } \\
\text { linker }\end{array}$ & Antitrombogenic activity tests/implantation in rats & 79 \\
\hline Titanium/PEG and Heparin & $\begin{array}{l}\text { carbodiimide covalent coupling } \\
\text { method }\end{array}$ & $\begin{array}{l}\text { APTT assay/HUVECs adhesion and proliferation } \\
\text { studies }\end{array}$ & 80 \\
\hline
\end{tabular}

APTT: activated partial thromboplastin time, HUVECs: Human Umbilical Vein Endothelial Cells, HASMCs: Human Artery smooth muscle cells, HMA: hexamethylenediamine. 


\section{Table 2}

Recent coating strategies to promote osseointegration

\begin{tabular}{lll}
\hline Substrate/Coating & Coating strategy & In vitro/in vivo studies \\
\hline Titanium/Sericin-RGD & $\begin{array}{l}\text { Sericin adsorption followed by } \\
\text { EDAC/NHS conjugation of RGD }\end{array}$ & Osteoblast differentiation, Alamar blue assay, RT-PCR \\
Titanium/Nano CaP crystals & Dual Acid etching & White rabbits tibial and femoral metaphysic implantation \\
Titanium/Ca-P-Si-Na & $\begin{array}{l}\text { Microarc oxidation, Steam hydro-thermal } \\
\text { treatment, heat treatment }\end{array}$ & $\begin{array}{l}\text { Rabbits implantation in tibia, Histological analysis, } \\
\text { implant push out force tests }\end{array}$ \\
Stainless Steel (316)/ FN7-10 & Passive adsorption & hMSCs differentiation studies, screw implantation in rats \\
\hline
\end{tabular}

FN7-10: recombinant fragment of human fibronectin, hMSCs Human mesenchymal stem cells, EDAC: ethyl (dimethylaminopropyl) carbodiimide and NHS: N-hydroxysulfosuccinimide, CaP: calcium phosphate 